\title{
Differential expression of pro- and antiangiogenic factors in mouse strain-dependent hypoxia-induced retinal neovascularization
}

\author{
Candy K Chan ${ }^{1,2}$, Lucia N Pham², Jiehao Zhou ${ }^{1,2}$, Christine Spee ${ }^{3}$, Stephen J Ryan ${ }^{2,3}$
} and David R Hinton ${ }^{1,2,3}$

${ }^{1}$ Department of Pathology, Keck School of Medicine, University of Southern California, Los Angeles, CA, USA; ${ }^{2}$ The Arnold and Mabel Beckman Macular Research Center at the Doheny Eye Institute, Keck School of Medicine, University of Southern California, Los Angeles, CA, USA and ${ }^{3}$ Department of Ophthalmology, Keck School of Medicine, University of Southern California, Los Angeles, CA, USA

\begin{abstract}
Clinical observations suggest that genetic factors may influence heterogeneity of angiogenic responses in cardiovascular disease, proliferative diabetic retinopathy, and neoplasia. Experiments among mouse strains using a corneal micropocket assay indicate that extent of angiogenesis may be genetically determined. Here, we established the strain-dependence of hypoxia-induced retinal angiogenesis in multiple mouse strains which paralleled the rank order found for bFGF-induced corneal angiogenesis. Using quantitative real-time RT-PCR, strain-related gene expression differences in retina/choroid between C57BL/6J and 129S3/SvIM, inbred strains with relatively low and high levels of angiogenesis, respectively, after $0,6,12,24,48$, and $96 \mathrm{~h}$ hypoxia were determined for vascular endothelial growth factor (VEGF) and angiopoietin-2 (Ang-2), angiogenic ligands potently induced by hypoxia, and for pigment epithelium-derived factor (PEDF) and thrombospondin-1 (TSP-1), endogenous broad-spectrum antiangiogenic factors. Indirect ELISA was used to correlate VEGF and PEDF protein levels with mRNA expression. At the onset of hypoxia, both PEDF and TSP-1 levels were increased over 15-fold and VEGF was increased over 10-fold compared to Ang-2 in both strains. At the onset of neovascularization (48 $\mathrm{h}$ ), both VEGF and Ang-2 mRNA levels were increased in the more angiogenic 129S3/ SvIM strain $(P<0.02)$, which was not observed among developmental control animals. PEDF expression was higher in the less angiogenic C57BL/6J strain at $6,12,24$, and $96 \mathrm{~h}$ hypoxia $(P<0.03)$, while TSP-1 expression was higher in C57BL/6J throughout the entire time course of hypoxia (4 days) compared to 129S3/SvIM $(P<0.02)$. Among developmental control animals, PEDF and TSP-1 expression was also increased at P14 and P16 in C57BL/6J strain compared to 129S3/SvIM $(P<0.02)$. Strain-dependent expression of both pro- and antiangiogenic growth factors may determine heterogeneity in the angiogenic response and potentially, susceptibility to angiogenesis-dependent diseases.

Laboratory Investigation (2005) 85, 721-733, advance online publication, 25 April 2005; doi:10.1038/labinvest.3700277
\end{abstract}

Keywords: angiogenesis; hypoxia; VEGF; PEDF: thrombospondin-1

Angiogenesis, the growth of new vessels from preexisting ones, is essential for fundamental physiologic processes including wound healing and the female reproductive cycle. Insufficient neovascularization exacerbates cardiovascular and peripheral

Correspondence: Dr DR Hinton, MD, Departments of Pathology and Ophthalmology, Keck School of Medicine, University of Southern California, 2011 Zonal Avenue, HMR 209, Los Angeles, CA 90033, USA.

E-mail: dhinton@usc.edu

Received 1 February 2004; revised 17 February 2005; accepted 21

February 2005; published online 25 April 2005 vascular diseases, ${ }^{1,2}$ while increased angiogenesis is implicated in the progression of tumor growth, macular degeneration, and diabetic retinopathy. ${ }^{3-5}$

Multiple clinical observations suggest that genetic factors may in part determine the severity of many angiogenesis-dependent diseases. Among patients with coronary artery disease, decreased formation of collateral vessels is associated with decreased levels of hypoxia-induced vascular endothelial growth factor (VEGF) mRNA, after normalizing for age, sex, diabetes, smoking, and hypercholesterolemia. ${ }^{6}$ The incidence of proliferative diabetic retinopathy is elevated in specific nonwhite populations after 
accounting for duration and control of diabetes. ${ }^{7}$ Among those with age-related macular degeneration, vision loss due to choroidal neovascularization is more prevalent in white compared to black populations after adjusting for age, sex, and smoking habits. ${ }^{8}$ Experiments among inbred strains of mice suggest that the heterogeneity of the extent of angiogenesis in response to exogenous growth factor stimulation is determined by genetic factors. ${ }^{9}$ In addition, strain-related differences in retinal angiogenesis between rat strains have been demonstrated. ${ }^{10,11}$ This suggests that genetic factors which influence the heterogeneity of the angiogenic response may in part determine the severity of a wide spectrum of angiogenesis-dependent diseases.

Understanding of the regulation of the angiogenic switch is still emerging. Multiple cytokines and growth factors stimulate angiogenesis including tumor necrosis factor alpha, interleukin-8, VEGF, and angiopoietins (Ang). ${ }^{12,13}$ Natural inhibitors of angiogenesis include endostatin, angiostatin, pigment epithelium-derived factor (PEDF), and thrombospondin-1 (TSP-1). ${ }^{14-17}$ Genetic influences on the regulation of pro- and antiangiogenic factors may provide a potential mechanism for strain-related heterogeneity in the angiogenic response.

We evaluated the influence of genetic background on retinal angiogenesis using a murine model of proliferative retinopathy. Here, we establish the first evidence of strain-dependent oxygen-induced retinal angiogenesis in multiple strains of mice: CD-1 (outbred), and C57BL/6J, AKR, DBA, and 129S3/ SvIM (inbred). We have further characterized hypoxia-induced pro- and antiangiogenic responses in C57BL/6J and 129S3/SvIM mouse strains. Similarly, these inbred strains were previously identified, and confirmed in our laboratory, ${ }^{18}$ to have divergently low (C57BL/6J) and high (129S3/SvIM) angiogenic responses in the corneal micropocket assay. ${ }^{9,19}$ Gene expression was determined for VEGF and Ang-2, ligands potently induced by hypoxia, and collaborative stimulators of angiogenesis. ${ }^{20-22}$ Strain-related influences were also determined for PEDF and TSP-1, potent natural inhibitors of angiogenesis previously implicated in retinal neovascularization. ${ }^{15,23-25}$ Elucidation of strain-related differences in the regulation of pro- and antiangiogenic growth factor responses during angiogenesis may provide insight into determination of angiogenic phenotype and subsequently, prediction of susceptibility to angiogenesis-dependent diseases.

\section{Materials and methods}

\section{Oxygen-Induced Retinopathy}

Retinal neovascularization was induced using a welldescribed murine model of hyperoxia-hypoxia-induced retinopathy in neonatal pups. ${ }^{26,27}$ C57BL/6J, AKR, DBA, and 129S3/SvIM inbred strains were obtained from The Jackson Laboratory (Bar Harbor,
ME, USA) and outbred CD-1 strain was obtained from Charles River Laboratories, Inc. (Wilmington, MA, USA). Briefly, postnatal day 7 (P7) mice and their nursing dam were exposed to hyperoxia $(75 \pm 3 \%)$ for 5 days and returned to room oxygen (relative hypoxia) at postnatal day 12 (P12). In this model, all exposed animals develop retinal angiogenesis, which reaches a maximum at postnatal day 17 (P17) and regresses by postnatal day 26 (P26). ${ }^{26}$

Neovascularization was quantified by three-dimensional (3D) confocal reconstruction microscopy of whole-mounted retinas on P17 (CD-1, $N=6$; C57BL/6J, $\quad N=15 ; \quad$ AKR,$\quad N=12 ; \quad$ DBA,$\quad N=16$; 129S3/SvIM, $N=8$ ). Differentiation of intraretinal and intravitreal neovascularization was determined using lectin histochemistry with serial sections in the two inbred mouse strains exhibiting the most divergent responses as quantified by confocal microscopy (C57BL/6J, $N=12$; 129S3/SvIM, $N=10$ ). Gene expression changes were evaluated from posterior eyecups of C57BL/6J and 129S3/SvIM inbred strains after 0 (P12), 6, 12, 24 (P13), 48 (P14), and $96 \mathrm{~h}$ (P16) of hypoxia and from developmental control animals at P12, P14, and P16. All experiments were performed in accordance with the University of Southern California, Keck School of Medicine Animal Care and Use Committee and the Association for Research in Vision and Ophthalmology Statement for the Use of Animals in Ophthalmology and Vision Research.

\section{Quantification of Retinal Angiogenesis by Confocal Microscopy}

Oxygen-induced retinal neovascularization was quantified using 3D reconstruction confocal microscopy as described previously. ${ }^{18}$ Briefly, experimental mice at P17 were anesthetized, and the femoral vein dissected and injected intravenously with $20 \mu \mathrm{g}$ of endothelial-specific, FITC-conjugated Griffonia simplicifolia lectin $\mathrm{I}^{-\mathrm{B}_{4}}\left(\mathrm{GSLI}^{\left.-\mathrm{B}_{4}\right)}\right.$ (Vector Laboratories, Burlingame, CA, USA). ${ }^{28}$ After $30 \mathrm{~min}$, the animals were killed, and eyes enucleated and fixed in $4 \%$ paraformaldehyde overnight at $4^{\circ} \mathrm{C}$. The cornea, sclera, choroid, and retinal pigment epithelium were dissected off the retina. Radial incisions were made to facilitate flat-mounting of the retinal specimen onto glass slides. Confocal scanning $(\times 2.5$ objective) was performed through the entire thickness of the vascularized retina at $4.5-5.5 \mu \mathrm{m}$ scanning plane intervals (Zeiss). Implicit vascular volume was derived by integration of the planar confocal vascular surface areas using 3D for LSM510 Software. Units for implicit volume were designated as VolSurfArea $\left(\mu \mathrm{m}^{2}\right) \pm$ s.e.m.

\section{Quantification of Intraretinal and Intravitreal Angiogenesis}

At P17, eyes from C57BL/6J or 129S3/SvIM mice were enucleated and frozen for cryostat sectioning. 
Cummulative neovascular area was quantified for every fifth serial section $(10 \mu \mathrm{m})$ from a reference point of nasal cornea to optic nerve. ${ }^{29}$ After fixation in acetone for $5 \mathrm{~min}$, frozen sections were incubated with $0.3 \% \mathrm{H}_{2} \mathrm{O}_{2} /$ phosphate-buffered saline (PBS) to inactivate endogenous peroxides. To detect endothelial cells, sections were incubated with $10 \mu \mathrm{g} / \mathrm{ml}$ biotinylated GSLI-B 4 (Vector Laboratories, Burlingame, CA, USA) in $1 \%$ bovine serum albumin (BSA)/PBS for $1 \mathrm{~h}$ at room temperature. Incubation with horseradish-peroxidase-conjugated streptavidin and subsequent 3-amino-9-ethylcarbazole (AEC) development (Vector Laboratories) allowed bright field visualization of endothelial cells. To distinguish intraretinal and intravitreal neovascularization, the inner limiting membrane (ILM) was similarly labeled with biotinylated Dolichos biflorus agglutinin lectin (DBA) ${ }^{30}(100 \mu \mathrm{g} / \mathrm{ml})$ (Vector Laboratories) and reaction product developed with an alkaline phosphatase-conjugated streptavidin chromagen substrate. The summed neovascular surface area was obtained (12 serial sections per eye) using ACIS Software (ChromaVision Medical Systems, Inc., San Juan Capistrano, CA, USA). Intraretinal neovascularization was defined as GSLI-positive labeling within the retina and external to the ILM. GSLI-positive structures including those contiguous with and protruding through the ILM into the vitreous was identified as intravitreal neovascularization. Values are reported as mean total neovascular surface area per eye $\left(\mu \mathrm{m}^{2}\right) \pm$ s.e.m.

\section{Quantitative Real-Time RT-PCR}

Relative quantitative expression of mRNA was evaluated using real-time RT-PCR. Posterior eyecups from each animal were harvested at specific time points during hypoxia or from developmental controls as described above and preserved in RNAlater (Ambion Inc., Austin, TX, USA). For each sample, total RNA was isolated from both posterior poles of individual mice with TRIzol Reagent (Invitrogen Life Technologies, Carlsbad, CA, USA) and contaminating genomic DNA removed with DNA-free (Ambion). Reverse transcription was performed using $1 \mu \mathrm{g}$ total RNA, oligo $(\mathrm{dT})_{15}$ primer (Promega Corp., Madison, WI, USA), and AMV reverse transcriptase (Promega). Real-time PCR reactions were performed in triplicate with the GeneAmp 5700 Sequence Detection System (Applied Biosystems, Foster City, CA, USA). Each $25 \lambda$ PCR reaction contained cDNA template, SYBR Green PCR Master Mix (Applied Biosystems), and $167 \mathrm{nM}$ gene-specific primers. Reaction conditions were as follows: $50^{\circ} \mathrm{C}$ for $2 \mathrm{~min}, 95^{\circ} \mathrm{C}$ for $10 \mathrm{~min}$, and 40 cycles of denaturation at $95^{\circ} \mathrm{C}$ for $15 \mathrm{~s}$ with annealing and extension at $60^{\circ} \mathrm{C}$ for $1 \mathrm{~min}$. Ribosomal $L-32$ was used as a reference (housekeeping) gene because the mRNA expression is unchanged by hypoxia (data not shown). The following primer sets were designed using Primer Express software (Applied
Biosystems): L-32 5'-TGGTTTTCTTGTTGCTCCCA TA-3' ${ }^{\prime}$ and $5^{\prime}$-GGGTGCGGAGAAGGTTCAA- $3^{\prime}$; VEGF $5^{\prime}$-CATCTTCAAGCCGTCCTGTGT- $3^{\prime}$ and $5^{\prime}$-CTCCA GGGCTTCATCGTTACA-3'; Ang-2 5'-GACTTCCAG AGGACGTGGAAAG- $3^{\prime}$ and $5^{\prime}$-CTCATTGCCCAGCC AGTACTC-3'; PEDF 5'-CACCCGACTTCAGCAAGA TTACT- $3^{\prime}$ and $5^{\prime}$-TCGAAAGCAGCCCTGTGTT- ${ }^{\prime}$; and TSP-1 $5^{\prime}$-ACTACGCTGGCTTTGTATTC- $3^{\prime}$ and $5^{\prime}$-GGACTGGGTGACTTGTTTCC-3' . Detection of product was set in the center of the linear portion of PCR amplification. The cycle at which each reaction reached the set threshold $\left(C_{\mathrm{T}}\right)$ was determined. Amplification efficiencies between primer pairs for genes of interest compared to that for $L-32$ reference gene, was evaluated by amplifying a dilution range of cDNA template. A plot of $\Delta C_{\mathrm{T}}$ on the $y$-axis and $\log$ (cDNA) on the abscissa generated a linear curve with $\mid$ slope $\mid<0.01$, verifying comparable primer pair amplification efficiencies between $L-32$ and genes of interest. To allow determination of relative abundance, comparable primer pair efficiencies were also determined for all permutations between genes of interest in comparison with each other. Relative fold differences of mRNA expression were determined by calculation of $\Delta \Delta C_{\mathrm{T}}$ compared to $\mathrm{C} 57 \mathrm{BL} / 6 \mathrm{~J}$ at $0 \mathrm{~h}$ hypoxia or developmental controls at P12. ${ }^{31}$

\section{Enzyme-Linked Immuno Sorbent Assays (ELISA)}

Both eyes from individual animals were pooled to obtain each sample and homogenized in buffer $(1 \mathrm{M}$ Tris-HCl, $1 \mathrm{M} \mathrm{MgCl}_{2}$, $0.5 \mathrm{mM}$ phenylmethylsulfonylfluoride) containing mixed protease inhibitors (Roche, Basel, Switzerland) for protein extraction at $48 \mathrm{~h}(\mathrm{C} 57 \mathrm{BL} / 6 \mathrm{~J}, N=7 ; 129 \mathrm{~S} 3 / \mathrm{SvIM}, N=4)$ and $96 \mathrm{~h}$ (C57BL/6J, $N=11 ; 129 \mathrm{~S} 3 / \mathrm{SvIM}, N=5$ ) after hypoxia and developmental controls. Protein homogenates were centrifuged at $14000 \times g$ for $10 \mathrm{~min}$ to remove tissue debris. Concentration of protein homogenates was performed using Microcon Centrifugal Filters (Millipore Corp., Bedford, MA, USA). To release protein bound to DNA, samples were treated with DNase I (Roche) for $20 \mathrm{~min}$ at $37^{\circ} \mathrm{C}$. Total protein concentration was determined.

VEGF and PEDF protein expression was assessed in triplicate by ELISA (R\&D Systems Inc., Minneapolis, MN, USA). The detection range of the VEGF ELISA was $3-500 \mathrm{pg} / \mu \mathrm{l}$, while the detection range for the PEDF ELISA was $2-825 \mathrm{ng} / \mu \mathrm{l}$. For both ELISAs, values were normalized to concentration of protein $/ \mu \mathrm{g}$ total protein \pm s.e.m.

Ang-2 or TSP-1 ELISAs were not performed because the levels of these proteins in pooled eyes from individual mice were below the detection levels of currently available assays.

\section{Statistical Analysis}

Statistical analyses were performed using SAS (SAS Institute, Cary, NC, USA). Values reported represent 
mean \pm s.e.m. Normal distribution of values within each group was tested using the Shapiro-Wilk statistic. In groups found to follow a non-normal distribution, nonparametric statistics were used. For nonparametric distributions, Kruskal-Wallis was used to test for overall differences between groups and Wilcoxon Rank Sum was used to test for differences between two groups. For normal distributions, parametric tests used were analysis of variance and paired $t$-tests. Comparisons between groups and between time points within each group were made using independent $t$-tests for equal or unequal variances. The Bonferonni correction was applied for multiple comparisons. Accepted level of significance for all tests was $\alpha=0.05$.

\section{Results}

\section{Neovascularization Following Oxygen-Induced Retinopathy}

Retinal angiogenesis was precisely characterized following 5 days hypoxia (P17) using lectin histochemistry, the time at which a maximal neovascular response is reached in this model. ${ }^{26}$ All exposed animals exhibited vascular tufts protruding past the ILM into the vitreous space, denoted as intravitreal neovascularization (Figure 1). In addition, larger retinal vessels were observed within the retina and deep to the ILM, termed intraretinal neovascularization. In contrast, P17 control animals showed no intravitreal neovascularization, and smaller, more regularly spaced, intraretinal vessels were present. No difference in retinal tissue thickness was observed between exposed animals compared to those of developmental controls.

\section{Hypoxia-Induced Retinal Neovascularization is Strain Dependent}

The influence of genetic background on hypoxiainduced retinal angiogenesis was evaluated using multiple strains of mice which were chosen to represent previously reported low, intermediate, and high angiogenic responders to bFGF in the corneal micropocket assay. ${ }^{9,18}$ Integrated vascularized surface area from oxygen-induced flat-mounted retinal specimens following 5 days hypoxia (P17) was quantified using endothelial-specific FITCGSLI by 3D reconstruction confocal microscopy (Figure 2). Neovascularization in 129S3/SvIM and DBA genetic backgrounds was increased 2.2-, and 1.7-fold, respectively, compared to C57BL/6J mice $(P<0.001 ; P<0.02)$. While retinal neovscularization in AKR mice was increased 2.0-fold compared to CD-1 $(P<0.02)$, no significant differences were observed in CD-1 and AKR strains compared to C57BL/6J. Hypoxia-induced retinal neovascularization resulted in the following strain-dependent rank order: $129 \mathrm{~S} 3 / \mathrm{SvIM}>\mathrm{DBA}>\mathrm{C}$ 7BL/6J $(P<0.04)$;
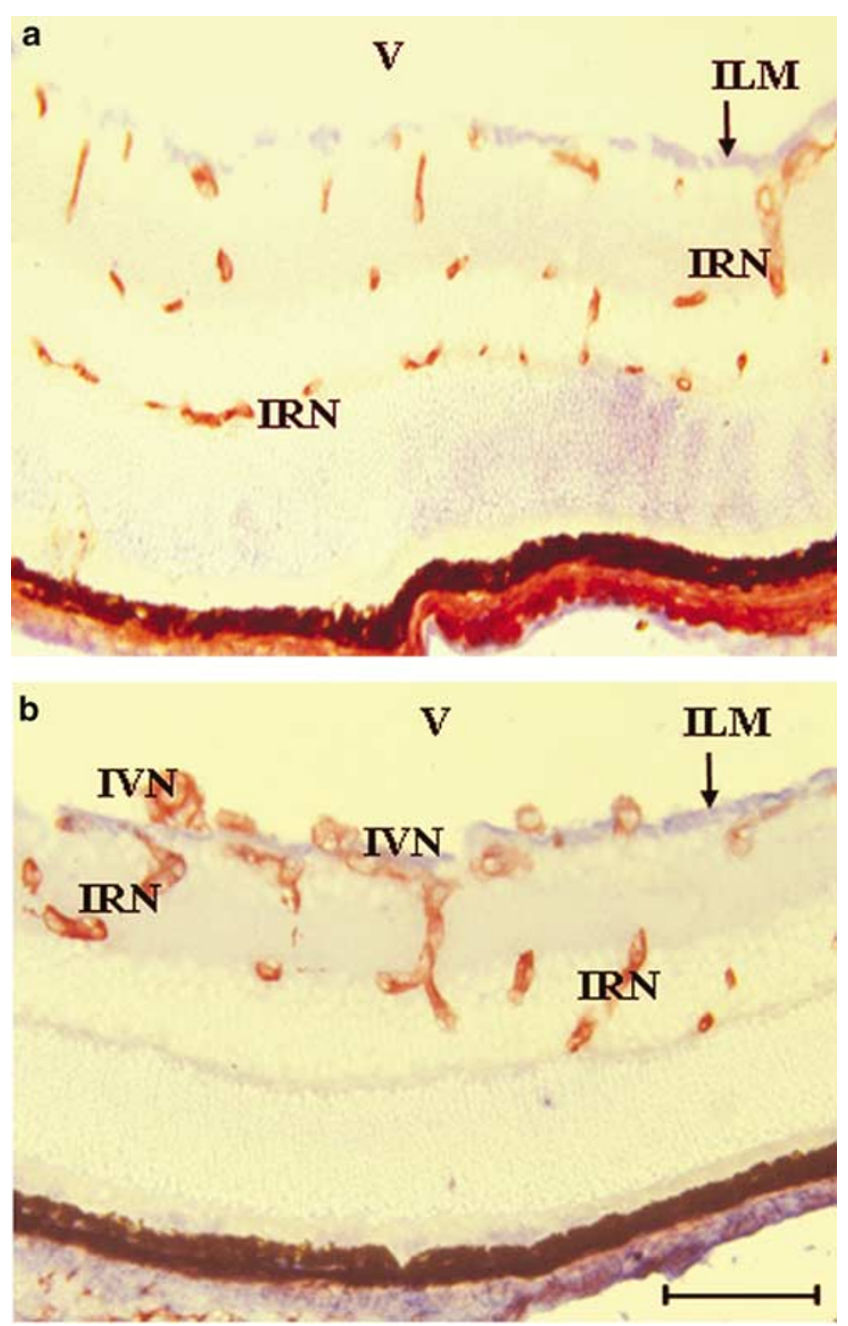

Figure 1 Lectin histochemistry of oxygen-induced retinal neovascularization. The inner limiting membrane (ILM) was identified with Dolichos biflorus agglutinin lectin (blue). Endothelial cells were stained using $G$. simplicifolia lectin I-B (red). (a) Normal developmental control retina at postnatal day 17 (P17). (b) Retina from an animal exposed to a model of oxygeninduced retinopathy at P17 showing intravitreal neovascularization (IVN) and intraretinal neovascularization (IRN). Vitreous (V). $\mathrm{Bar}=100 \mu \mathrm{m}$.

129S3/SvIM $>$ CD-1 $(P<0.001) ; 129$ S3/SvIM $>$ AKR $(P<0.001)$; DBA $>$ CD-1 $(P<0.004)$; DBA $>$ C57BL $/ 6 \mathrm{~J}$ $(P<0.02)$; AKR $>$ CD-1 $(P<0.002)$.

\section{Intraretinal and Intravitreal Angiogenesis is Increased}

To differentiate intraretinal from intravitreal angiogenesis, histologic serial sections were evaluated in C57BL/6J and 129S3/SvIM; inbred strains with the most divergent angiogenic response to hypoxia (Figure 3a). A 2.7-fold increase in intravitreal angiogenesis among 129S3/SvIM mice compared to C57BL/6J was observed (Figure 3b; $P<0.0001$ ). Intraretinal neovascularization in 129S3/SvIM was increased $38 \%$ compared to C57BL/6J strain (Figure 3c, $P<0.0009$ ). The increased intravitreal neovascular tufts contained more endothelial cells 


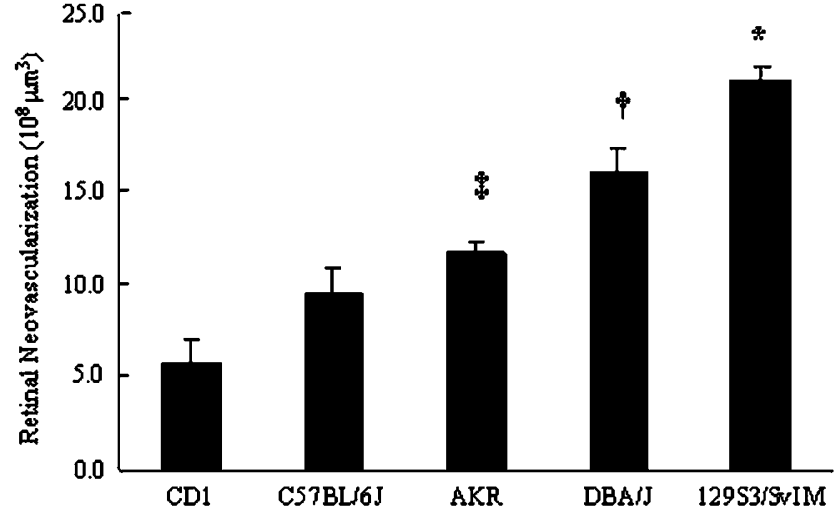

Figure 2 Hypoxia-induced retinal neovascularization is strain dependent. Quantification of retinal neovascularization in flatmounted specimens in multiple strains of mice following 5 days hypoxia (P17) using 3D reconstruction confocal microscopy (CD-1, $N=6$; C57BL/6J, $N=15 ;$ AKR, $N=12 ;$ DBA, $N=16$; 129S3/SvIM, $N=8$ ). Retinal vasculature was detected with endothelial-specific FITC-G. simplicifolia lectin I-B ${ }_{4}$. Although retinal neovascularization in AKR mice was increased 2.0-fold compared to CD-1 $(\ddagger P<0.02)$, no significant differences were observed in CD1 and AKR compared to C57BL/6J $(P>0.05)$. Neovascularization in 129S3/SvIM and DBA genetic backgrounds was increased 2.2-, and 1.7-fold, respectively, compared to C57BL/6J mice $\left({ }^{*} P<0.001 ; \dagger P<0.02\right)$.

and protruded further into the vitreous cavity in 129S3/SvIM compared to C57BL/6J mice.

PEDF and TSP-1 mRNA Levels are Increased Relative to VEGF and Ang-2 at the Onset of Hypoxia in Both Strains

To evaluate the relative abundance of pro- compared to antiangiogenic growth factors in oxygen-induced retinopathy, mRNA levels of VEGF, PEDF, and TSP-1 relative to Ang-2 were determined at $0 \mathrm{~h}$, the onset of hypoxia (Figure 4). Each sample reflects gene expression from pooled posterior poles (right and left) of a single mouse. Similar efficiencies between primer pair sets were determined for all permutations between genes of interest to validate intergene comparisons. No strain-related differences in VEGF, Ang-2, PEDF, or TSP-1 were observed between these strains. However, both C57BL/6J and 129S3/SvIM strains demonstrated increased relative expression of angiogenic inhibitors compared to that of proangiogenic growth factors. PEDF expression was increased over 20-fold compared to Ang-2 in both inbred strains $(P<0.0001)$. TSP-1 expression was increased 20- and 15-fold compared to that of Ang-2 in C57BL/6J and 129S3/SvIM respectively $(P<0.0001 ; P<0.0001)$. In comparison, VEGF expression was increased 10 -fold in both strains compared to that of Ang-2 $(P<0.0001)$.

\section{VEGF mRNA Expression is Increased in 129S3/SvIM at $48 \mathrm{~h}$}

Relative fold differences in mRNA levels after 0-96h hypoxia were obtained by comparison to

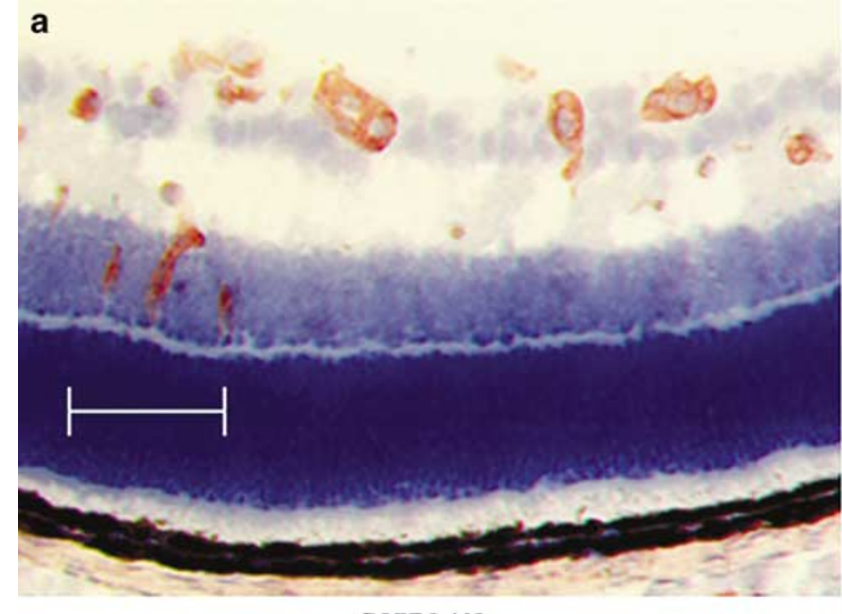

C57BL/6J

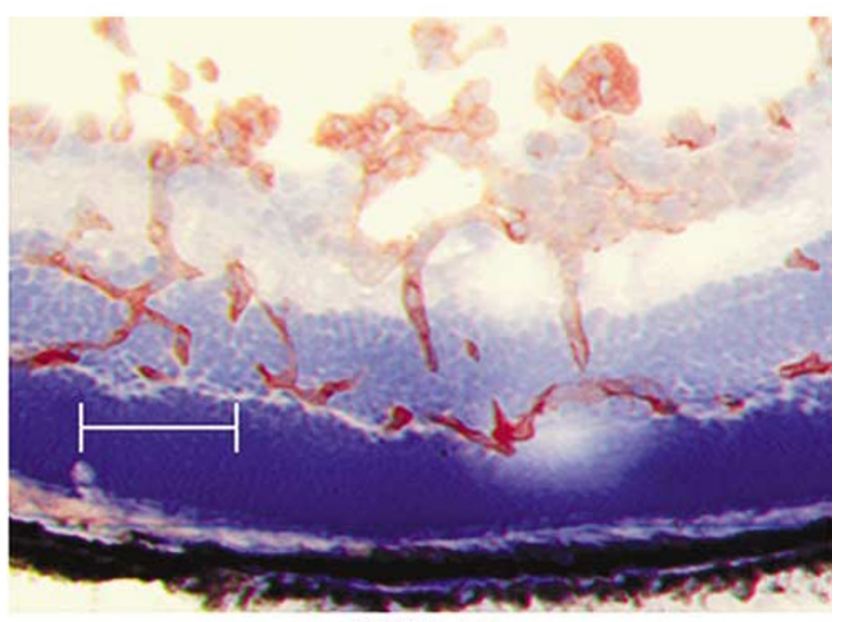

$129 \mathrm{~S} 3 / \mathrm{SvIM}$
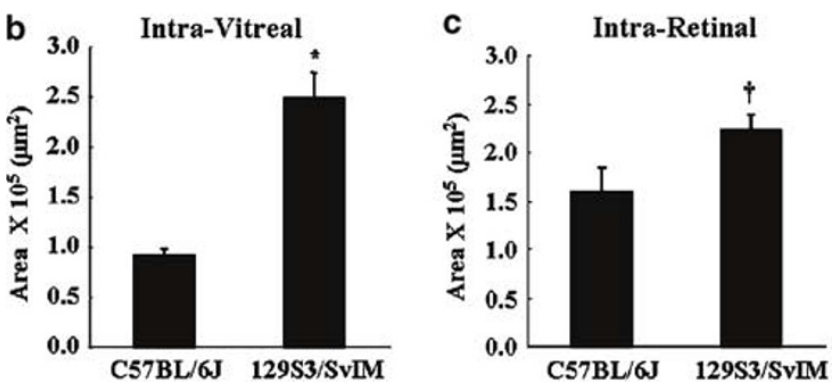

Figure 3 Intraretinal and intravitreal angiogenesis is increased in 129S3/SvIM. (a) Retinal neovascularization at P17 in C57BL/6J $(N=12)$ and $129 \mathrm{~S} 3 / \mathrm{SvIM}(N=10)$ strains. Endothelial cells were identified with $G$. simplicifolia lectin $\mathrm{I}^{-B_{4}}$ (red) and sections counterstained with hematoxylin (blue). (b) Quantification of total neovascular surface area from serial sections. Intravitreal neovascularization was increased 2.7 -fold in 129S3/SvIM $(N=10)$ compared to C57BL/6J $(N=12)$ mouse strain $\left({ }^{*} P<0.0001\right)$. (c) Intraretinal neovascularization was increased nearly $40 \%$ in $129 \mathrm{~S} 3 / \mathrm{Sv}(N=10)$ compared to C57BL/6J $(N=12)(\dagger P<0.0009)$. $\mathrm{Bar}=100 \mu \mathrm{m}$.

C57BL/6J at $0 \mathrm{~h}$ (P12) hypoxia after normalizing with L-32. Northern blot studies have shown that levels of $\mathrm{VEGF}^{32}$ and Ang-2 ${ }^{33}$ are expressed at steady state during this time period in developmental control 


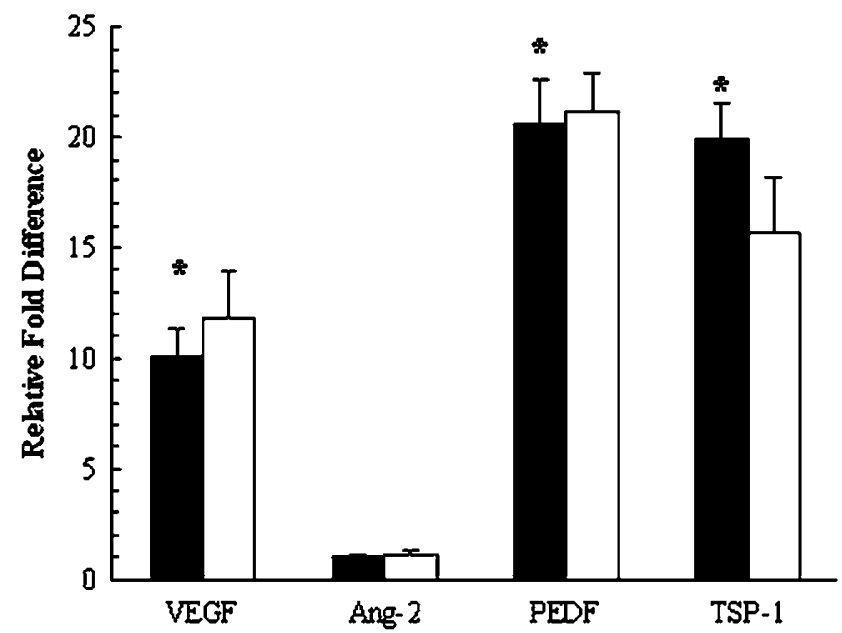

Figure 4 Gene expression in C57BL/6J and 129S3/SvIM at $0 \mathrm{~h}$ hypoxia. Relative mRNA levels of VEGF, Ang-2, PEDF, and TSP-1 were determined for C57BL/6J $(\square N=10)$ and 129S3/SvIM ( $\square$ $N=15$ ) at $0 \mathrm{~h}$ hypoxia using quantitative real-time RT-PCR. No strain-related differences in Ang-2, VEGF, PEDF, and TSP-1 gene expression is observed at the onset of hypoxia. In both inbred strains, VEGF expression was increased over 10-fold compared to that of Ang-2 $\left({ }^{*} P<0.0001\right)$, while PEDF and TSP-1 expression was increased over 20- and 15-fold compared to Ang-2 mRNA levels, respectively $\left({ }^{*} P<0.0001\right)$.

animals. The expression levels of VEGF mRNA in C57BL/6J and 129S3/SvIM were similar at 0, 6, 12, 24, and $96 \mathrm{~h}$ (Figure 5a) and were biphasic. An initial three-fold increase in VEGF expression was reached at $6 \mathrm{~h}(\mathrm{C} 57 \mathrm{BL} / 6 \mathrm{~J}, P<0.005 ; 129 \mathrm{~S} 3 / \mathrm{SvIM}$, $P<0.02$ ), followed by a decline at $24 \mathrm{~h}$. In 129S3/ SvIM (48 h), VEGF returned to similar levels seen at $6 \mathrm{~h}$ and remained elevated through $96 \mathrm{~h}$. The late phase increase in VEGF expression was not observed until $96 \mathrm{~h}$ in C57BL/6J mice.

\section{Late Regulation of Ang-2 is Increased in 129S3/SvIm}

Ang-2 expression remained constant throughout the first $24 \mathrm{~h}$ of hypoxia but increased in both strains at 48 and $96 \mathrm{~h}$ (C57BL/6J, $P<0.005 ; 129 \mathrm{~S} 3 / \mathrm{SvIM}$, $P<0.005)$. The relative expression levels of Ang-2 at these time points remained much reduced compared to that of VEGF, PEDF, or TSP-1. At $48 \mathrm{~h}$ there was a $22 \%$ increase in Ang-2 expression in $129 \mathrm{~S} 3 / \mathrm{SvIM}$ compared to $\mathrm{C} 57 \mathrm{BL} / 6 \mathrm{~J} \quad(P<0.03)$ (Figure 5b); coinciding with elevated relative levels of VEGF $(P<0.008)$ (Figure 5a). By $96 \mathrm{~h}$, strainrelated differences between these strains were not significant $(P=0.13)$.

\section{Increased Relative PEDF Expression in C57BL/6J}

A biphasic PEDF expression pattern was observed in both strains (Figure 5c). However, unlike VEGF, PEDF expression was elevated throughout much of the time course in C57BL/6J strain compared to
129S3/SvIM. Both inbred strains reached an initial peak of PEDF expression by $6 \mathrm{~h}$ hypoxia (C57BL/6J: 2.0-fold, $P<0.0001$ and 129S3/SvIM: 1.6-fold, $P<0.001$ compared to $0 \mathrm{~h}$ ), followed by declining mRNA levels through $24 \mathrm{~h}$. In 129S3/SvIM, PEDF expression returned to levels seen at baseline $(0 \mathrm{~h})$ by 12 and $24 \mathrm{~h}(P=0.16$ and 0.94$)$; however, mRNA levels in C57BL/6J at 12 and $24 \mathrm{~h}$ remained elevated compared to $0 \mathrm{~h}(P<0.001)$. A second increase in PEDF expression was observed at $48 \mathrm{~h}$ in both C57BL/6J and 129S3/SvIM strains. While changes in PEDF expression were not observed in 129S3/ SvIM animals from 48-96h, PEDF mRNA levels continued to increase in C57BL/6J. At $48 \mathrm{~h}$ hypoxia, the time at which increased VEGF and Ang-2 expression in 129S3/SvIM was found (Figure 5a and b), no strain-related differences in PEDF mRNA levels were observed. Overall, PEDF mRNA levels were significantly decreased in $129 \mathrm{~S} 3 / \mathrm{SvIM}$ at 12 , 24 , and $96 \mathrm{~h}$ compared to C57BL/6J $(P<0.01)$.

\section{Increased Relative TSP-1 Expression in C57BL/6J}

Both inbred strains demonstrated decreased levels of TSP-1 expression following hypoxia (Figure 5b); however, responses in C57BL/6J were delayed compared to 129S3/SvIM. 129S3/SvIM mice showed 0.6-fold decreased TSP-1 levels beginning at $6 \mathrm{~h}$ and sustained through $24 \mathrm{~h}$ hypoxia compared to $0 \mathrm{~h}(P<0.05)$. However, mRNA expression levels in C57BL/6J did not decrease until $24 \mathrm{~h}$ and remained downregulated through $48 \mathrm{~h}$ compared to $0 \mathrm{~h}(P<0.04)$. Furthermore, while decreased TSP-1 expression was followed by subsequent mRNA increases in both strains, 129S3/SvIM mice returned to similar TSP-1 levels seen at baseline $(0 \mathrm{~h})$ by $48 \mathrm{~h}$ $(P=0.12)$. This baseline level of TSP-1 mRNA expression in 129S3/SvIM was maintained through $96 \mathrm{~h} \quad(P=0.67)$. In contrast, C57BL/6J animals showed increased 1.6-fold TSP-1 expression at $96 \mathrm{~h}$, beyond that observed for $0 \mathrm{~h}(P<0.04)$. TSP-1 expression was increased 2.6-, 2.2-, 1.8-, and 2.2fold in C57BL/6J compared to 129S3/SvIM at 6, 12, 24 , and $96 \mathrm{~h}$, respectively $(P<0.0007)$. At $48 \mathrm{~h}$, TSP-l mRNA levels were increased 1.4-fold in C57BL/6J compared to $129 \mathrm{~S} 3 /$ SvIM mice $(P<0.03)$.

\section{VEGF and PEDF Protein Levels Correlate with Differences in mRNA Expression}

VEGF protein levels were increased in 129S3/SvIM animals at $48 \mathrm{~h}(P<0.05)$ (Figure 6a), and although they remained slightly elevated compared to C57BL/ $6 \mathrm{~J}$, this resulted in no significant differences at $96 \mathrm{~h}$ $(P=0.15)$ (Figure 6b). Each sample reflects protein levels from pooled posterior poles (right and left) of a single mouse. Since no strain differences in mRNA levels of VEGF were observed between C57BL/6J and 129S3/SvIM developmental control animals at P12, P14, and P16 (see below), VEGF protein levels 

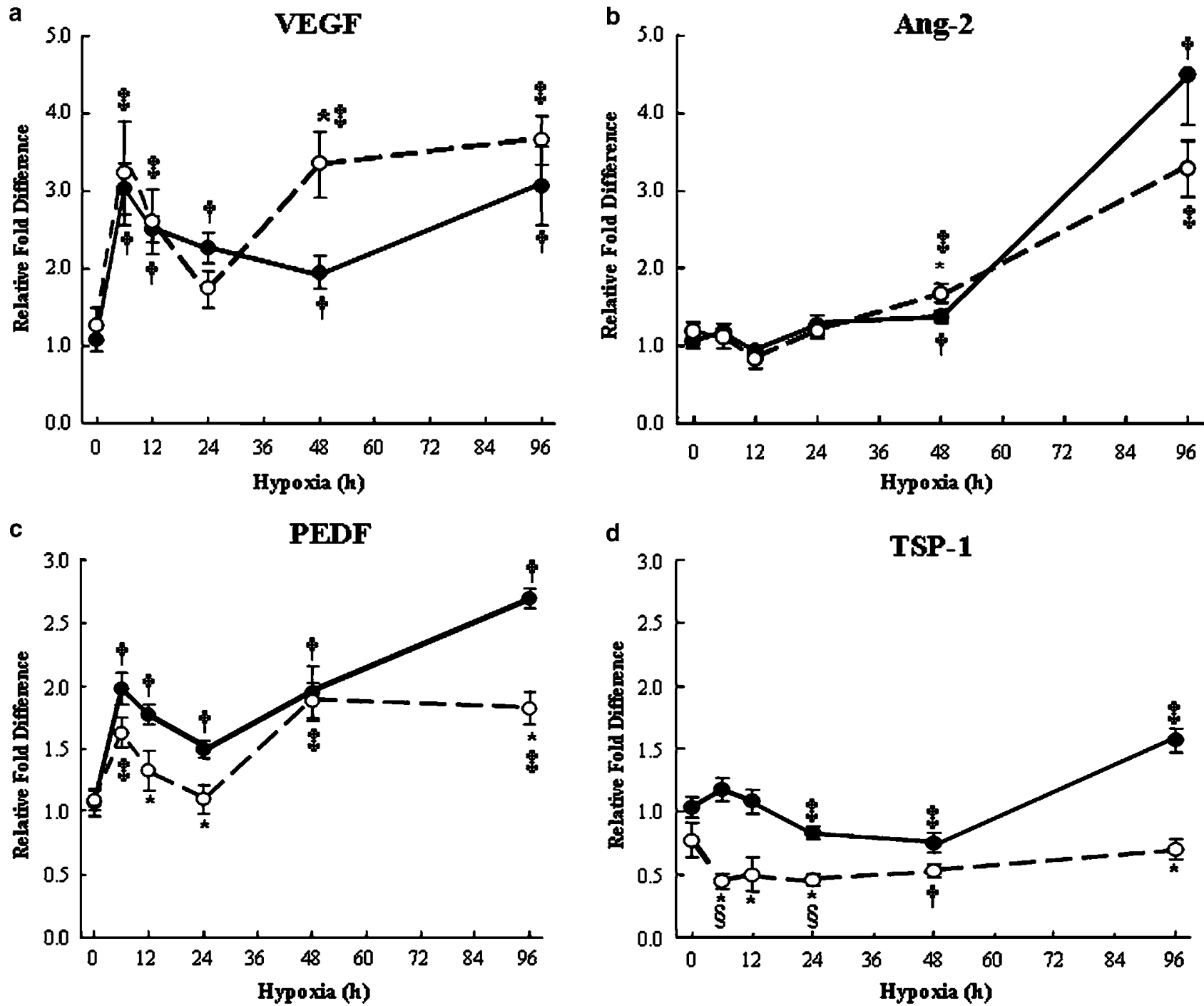

Figure 5 Relative gene expression in C57BL/6J and 129S3/SvIM from 0 to $96 \mathrm{~h}$ hypoxia. Expression of VEGF, Ang-2, PEDF, and TSP-1 mRNA of posterior poles from individual animals using quantitative real-time RT-PCR at 0, 6, 12, 24, 48, and $96 \mathrm{~h}$ after hypoxia (- - C57BL/6J, $N=10,12,19,15,14,8 ;---\bigcirc--129 S 3 / S v I M, N=15,10,8,9,12,7)$. (a) Strain-dependent differences in VEGF expression were seen at $48 \mathrm{~h}$, at the onset of angiogenesis. $\left({ }^{*} P<0.008\right.$ compared to C57BL/6J) $(\dagger P<0.001$ compared to C57BL/6J at $0 \mathrm{~h} ; \ddagger P<0.009$ compared to $129 \mathrm{~S} 3 / \mathrm{SvIM}$ at $0 \mathrm{~h}$ ). (b) With the exception at $48 \mathrm{~h}$, hypoxia-induced Ang-2 expression was similar between C57BL/6J and 129S3/SvIM inbred strains ( ${ }^{*} P<0.03$ compared to C57BL/6J) $(\dagger P<0.005$ compared to C57BL/6J at 0 h; $\ddagger P<0.005$ compared to 129 S3/ SvIM at $0 \mathrm{~h}$ ). (c) PEDF expression was elevated in the less angiogenic C57BL/6J strain compared to 129S3/SvIM following hypoxia $\left({ }^{*} P<0.01\right.$ compared to C57BL/6J) $(\dagger P<0.001$ compared to C57BL/6J at $0 \mathrm{~h} ; \ddagger \mathrm{p}<0.001 \mathrm{compared}$ to $129 \mathrm{~S} 3 / \mathrm{SvIM}$ at $0 \mathrm{~h})$. (d) TSP-1 mRNA levels were consistently elevated throughout the time course in C57BL/6J compared to $129 \mathrm{~S} 3 / \mathrm{SvIM}\left({ }^{*} P<0.0007\right.$ and $\dagger P<0.03 \mathrm{compared}$ to $\mathrm{C} 57 \mathrm{BL} / 6 \mathrm{~J})(\ddagger P<0.04$ compared to $\mathrm{C} 57 \mathrm{BL} / 6 \mathrm{~J}$ at $0 \mathrm{~h} ; \S P<0.05$ compared to $129 \mathrm{~S} 3 / \mathrm{SvIM}$ at $0 \mathrm{~h})$.

were assessed in control animals at a single time point, P12. No significant differences in VEGF protein expression was observed between C57BL/ 6J and 129S3/SvIM mouse strains at P12 in developmental control animals (data not shown).

Proteins levels for PEDF during hypoxia also correlated with mRNA expression data. At $48 \mathrm{~h}$, no significant difference in PEDF levels was found between $\mathrm{C} 57 \mathrm{BL} / 6 \mathrm{~J}$ and $129 \mathrm{~S} 3 / \mathrm{SvIM}$ pups $(P=0.24)$ (Figure 6c). However, PEDF protein was decreased 0.6-fold in 129S3/SvIM compared to C57BL/6J mice at $96 \mathrm{~h}(P<0.009)$ (Figure 6d). Since mRNA levels of PEDF among developmental control animals in
C57BL/6J and 129S3/SvIM strains begin to diverge to significant levels at P14 (see below), PEDF protein levels were assessed at both P12 and P14. No significant differences in PEDF protein was observed in developmental control animals at P12 or P14 between C57BL/6J and 129S3/SvIM (data not shown).

\section{VEGF/PEDF Protein Levels in 129S3/SvIM Strain is Increased at 48 and $96 \mathrm{~h}$ Hypoxia}

A ratio of VEGF to PEDF protein levels was determined for both C57BL/6J and 129S3/SvIM 

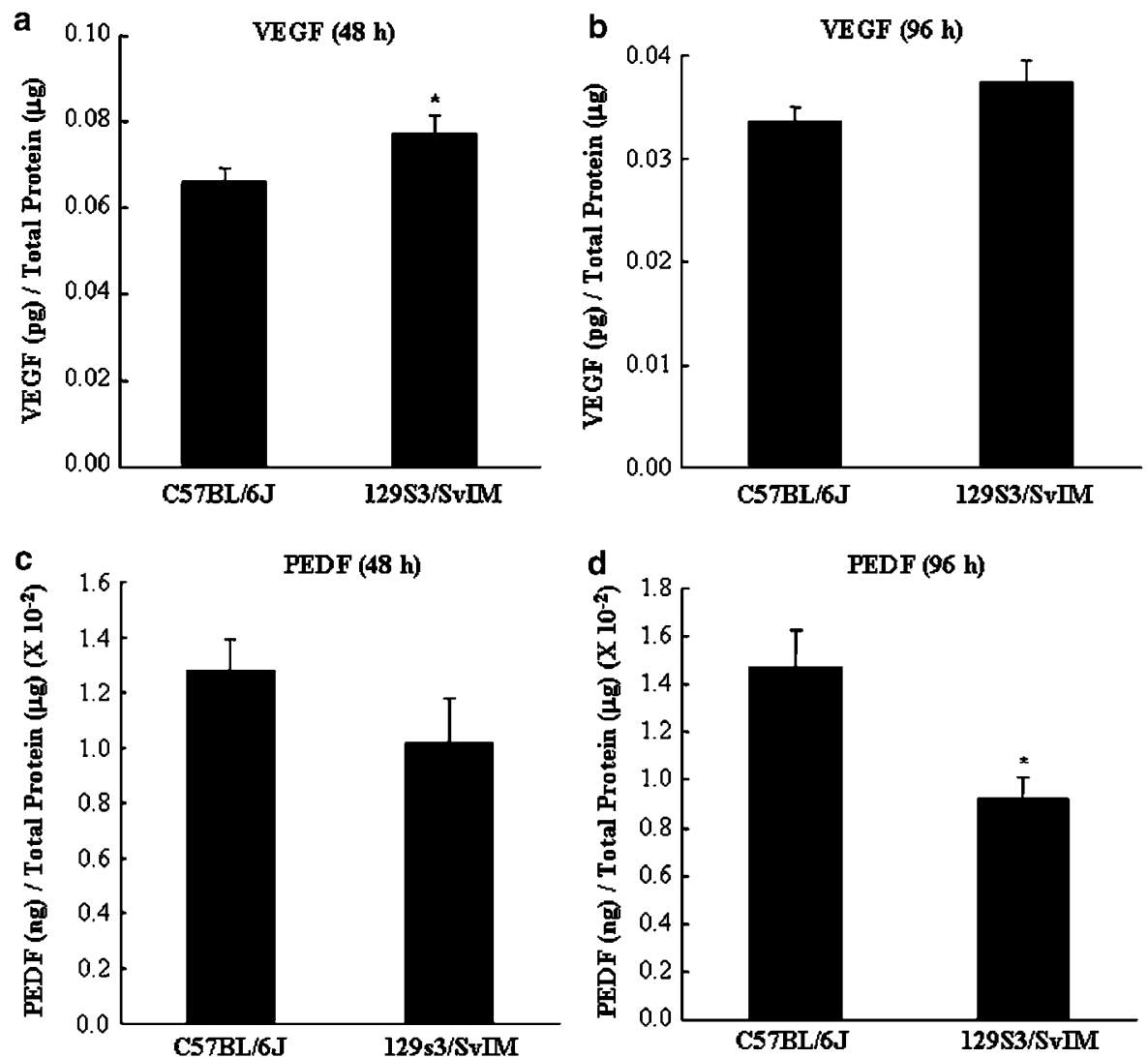

Figure 6 VEGF and PEDF protein levels induced by hypoxia are strain dependent. Protein levels determined at 48 h (C57BL/6J, $N=7$; $129 \mathrm{~S} 3 / \mathrm{SvIM}, N=4)$ and $96 \mathrm{~h}$ (C57BL/6J, $N=11 ; 129 \mathrm{~S} 3 / \mathrm{SvIM}, N=5$ ) by indirect ELISA. (a) At 48 h hypoxia, VEGF protein levels were increased in the more angiogenic 129S3/SvIM strain compared to C57BL/6J ( $\left.{ }^{*} P<0.05\right)$. (b) VEGF expression was similar in both inbred strains at $96 \mathrm{~h}$. (c) PEDF shows a small, but insignificant increase in C57BL/6J animals at $48 \mathrm{~h}$ compared to $129 \mathrm{~S} 3 / \mathrm{SvIM}$. (d) At $96 \mathrm{~h}$ following hypoxia, PEDF was increased in the less angiogenic C57BL/6J strain compared to 129S3/SvIM ( $\left.{ }^{*} P<0.009\right)$.

strains to assess the relative levels of pro- and antiangiogenic growth factor expression at $48 \mathrm{~h}$ and $96 \mathrm{~h}$ hypoxia (Figure 7). VEGF/PEDF was increased 1.5- and 1.8-fold at both 48 and $96 \mathrm{~h}$ hypoxia among $129 \mathrm{~S} 3 / \mathrm{SvIM}$ mice compared to that of C57BL/6J $(P<0.0003 ; P<0.0001)$. No significant differences in VEGF/PEDF were observed in developmental control animals at P14 between C57BL/6J and 129S3/SvIM (data not shown).

\section{Pro- and Antiangiogenic Growth Factor mRNA Expression Levels in Developmental Control Animals}

To assess the endogenous levels of gene expression in naïve developmental control C57BL/6J and 129S3/SvIM animals, VEGF, Ang-2, PEDF, and TSP-1 levels were determined at P12, P14, and P16 by quantitative real time RT-PCR (Figure 8). While mRNA levels of VEGF in C57BL/6J developmental control mice were increased 2.0- and 2.2-fold at P14 and P16 compared to P12 $(P<0.0001 ; P<0.0005)$, respectively, no strain differences between C57BL/6J and 129S3/SvIM were observed at these time points
(Figure 8a). Similarly, Ang-2 mRNA levels increased 1.5- and 1.4-fold in C57BL/6J developmental control animals at $\mathrm{P} 14$ and $\mathrm{P} 16$ compared to $\mathrm{P} 12(P<0.0001$; $P<0.009$ ), respectively, but did not result in strain differences between C57BL/6J and 129S3/SvIM strains (Figure 8b). In contrast, although both PEDF and TSP-1 expression levels increased during development, strain differences in developmental control animals were observed at both P14 and P16. PEDF expression levels in developmental control C57BL/6J mice increased 1.8- and 2.4-fold at P14 and P16, respectively, compared to $\mathrm{P} 12(P<0.0002$; $P<0.0001$ ) (Figure 8c). However, PEDF mRNA levels in control 129S3/SvIM animals did not differ significantly between $\mathrm{P} 14$ and $\mathrm{P} 12 \quad(P=0.08)$. In addition, PEDF expression increased to only 1.8fold in control 129S3/SvIM mice at P16 compared to P12 $(P<0.02)$. PEDF mRNA expression between inbred strains in developmental control animals at P14 and P16 was increased 1.5- and 1.7-fold, respectively, in C57BL/6J mice compared to 129S3/ SvIM strain $(P<0.02 ; P<0.0004)$. Similarly, TSP-1 expression in developmental control C57BL/6J animals increased 2.0- and 2.7-fold at P14 and 
a
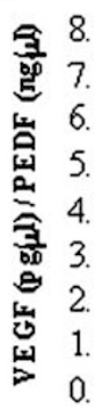

7.00
7.00
6.00
5.00
4.00
3.00
2.00
1.00
0.00

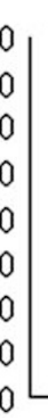

.

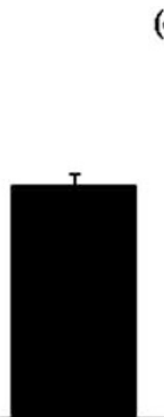

$(48 \mathrm{~h})$

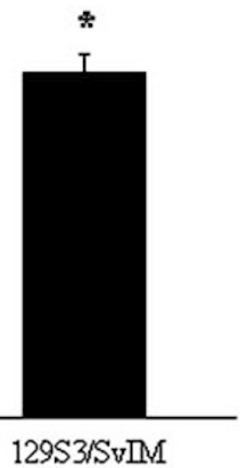

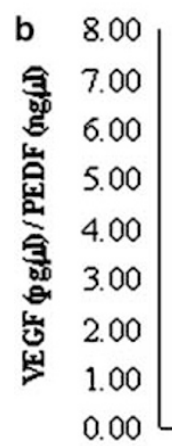

$(96 \mathrm{~h})$

Figure 7 Protein levels of VEGF/PEDF in 129S3/SvIM strain are increased at 48 and $96 \mathrm{~h}$ hypoxia. Ratios of protein levels for VEGF/PEDF was determined following $48 \mathrm{~h}$ (C57BL/6J, $N=7$; 129S3/SvIM, $N=4$ ) or $96 \mathrm{~h}$ (C57BL/6J, $N=11 ; 129 \mathrm{~S} 3 /$ SvIM, $N=5$ ) of hypoxia in C57BL/6J and 129S3/SvIM strains by indirect ELISA. (a) At $48 \mathrm{~h}$ hypoxia, VEGF/PEDF protein levels in 129S3/ SvIM mice were increased 1.5-fold compared to C57BL/6J strain $\left({ }^{*} \mathrm{P}<0.0003\right)$. (b) At $96 \mathrm{~h}$ hypoxia, VEGF/PEDF protein in $129 \mathrm{~S} 3 /$ SvIM animals was increased 1.8-fold compared to C57BL/6J mice $\left({ }^{*} P<0.0001\right)$.

P16, respectively, compared to $\mathrm{P} 12 \quad(P<0.0001$; $P<0.0006$ ) (Figure 8d). During development in 129S3/SvIM mice, TSP-1 mRNA levels increased only 1.7 -fold at P16 compared to P12 $(P<0.007)$ and did not show any significant differences at P14 compared to P12 $(P=0.08)$. TSP-1 expression in developmental control C57BL/6J mice at P14 and P16 was increased 1.4- and 1.9-fold, respectively, compared to $129 \mathrm{~S} 3 / \mathrm{SvIM}$ animals $(P<0.02$; $P<0.004)$.

\section{Discussion}

This study provides evidence that genetic background influences the extent of new blood vessel formation in the retina after hyperoxia-hypoxia and expression of pro- and antiangiogenic genes. The strain dependence of hypoxia-induced retinal angiogenesis in multiple mouse strains paralleled previous results found for bFGF-induced corneal angiogenesis. ${ }^{9,18}$ Moreover, the 2.7-fold increase in intravitreal neovascularization found in this study, is consistent with previously reported 2.8 -fold increased corneal angiogenesis in 129S3/SvIM compared to C57BL/6J strain. ${ }^{9}$ Although VEGF expression has been well characterized in this model for C57BL/6J mice, ${ }^{32}$ the biphasic pattern of VEGF expression observed in this study for both inbred strains, has not been reported and may represent an initial hypoxia-induced peak of VEGF expression followed by a decline in mRNA levels due to receptor-activated negative feedback. ${ }^{34}$ The initial peak in VEGF expression may be associated with increased vascular congestion and dilatation observed in the retina in this model prior to onset of angiogenesis. ${ }^{26}$ The second increase observed in VEGF expression following $48 \mathrm{~h}$, may be associated with initiation of angiogenesis in response to prolonged hypoxia. This second increase in VEGF levels is consistent with observations that retinal neovascularization begins at $48 \mathrm{~h}(\mathrm{P} 14){ }^{26}$ Strainrelated increases in VEGF mRNA expression among 129S3/SvIM mice compared to C57BL/6J $(P<0.008)$ may reflect earlier and more pronounced endothelial activation and VEGF production in the more angiogenic 129S3/SvIM strain.

Consistent with studies in Ang-2-deficient mice showing that Ang-2 is not required for retinal vascular regression, but is necessary for ischemiainduced neovascularization, the current study shows that Ang-2 levels are low at $0 \mathrm{~h}$ relative hypoxia, and are upregulated at the initiation of angiogenesis at $48 \mathrm{~h}$ hypoxia $(P<0.005) .{ }^{33,34}$ Ang-2 mRNA levels were slightly (but significantly) increased in the more angiogenic 129S3/SvIM strain at $48 \mathrm{~h}$ compared to C57BL/6J $(P<0.03)$. In addition, the relative increase in Ang-2 expression between 48 and $96 \mathrm{~h}$, suggests an increased need for Ang-2 during the growth phase of angiogenesis.

Moreover, the absence of significant strain-related differences in expression of proangiogenic VEGF and Ang-2 mRNA levels in developmental control mice at P12, P14, and P16 suggest that straindependent differential regulation of VEGF and Ang-2 is specifically activated or unmasked during hypoxia-induced angiogenesis.

Strain-related differences in regulation of antiangiogenic factors PEDF and TSP-1 between inbred strains occurred earlier and were more prolonged compared to those observed for VEGF and Ang-2. Early elevated levels of antiangiogenic factors in C57BL/6J mice may dampen the subsequent angiogenic response. Throughout the first $24 \mathrm{~h}$ of hypoxia, prior to the onset of angiogenesis, increased levels of both PEDF and TSP-1 were observed in C57BL/6J compared to 129S3/SvIM while VEGF and Ang-2 expression were similar. At $48 \mathrm{~h}$ hypoxia, the beginning of the neovascular response in this model, no differences in PEDF mRNA levels were observed between inbred strains, however, both VEGF and Ang-2 expression were increased in the more angiogenic 129S3/SvIM strain. The biphasic pattern observed for both PEDF and VEGF is consistent with induction of PEDF by VEGF found in vitro. ${ }^{35}$ 

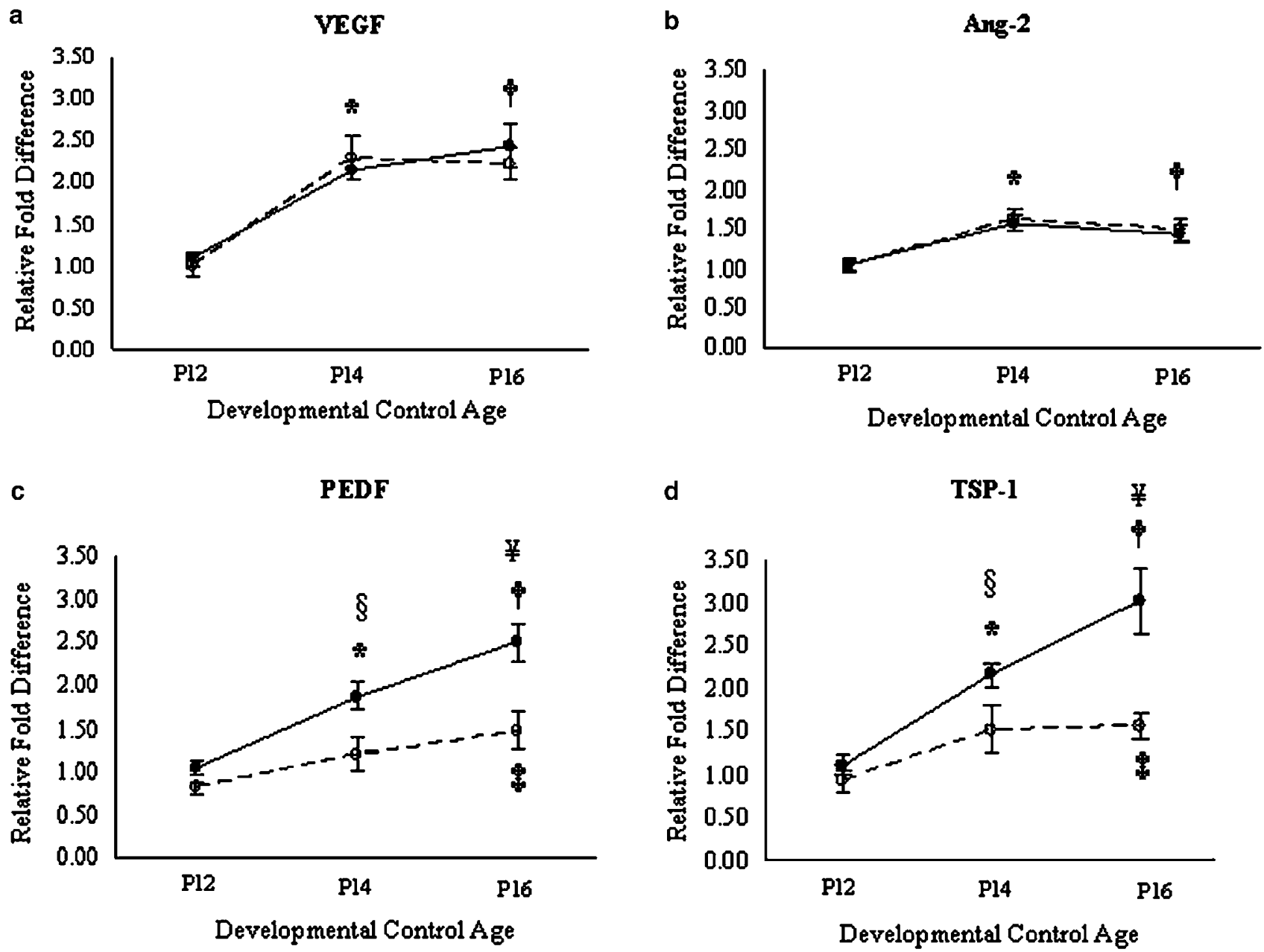

Figure 8 Relative gene expression in developmental control animals. Expression of VEGF, Ang-2, PEDF, and TSP-1 mRNA from posterior poles of individual developmental control animals using quantitative real time RT-PCR at P12, P14, and P16. ( - - C57BL/6J, N=16, 16, 10; - - - - 129S3/SvIM, $N=8$, 8, 9). (a) Although VEGF mRNA levels in C57BL/6J mice were increased 2.0- and 2.4-fold at P14 and P16, respectively, compared to P12 $\left({ }^{*} P<0.0001\right.$; $\left.† P<0.0005\right)$, no strain-dependent differences between C57BL/6J and 129S3/SvIM developmental control mice were seen at P12, P14, and P16. (b) Ang-2 mRNA levels also increased 1.5- and 1.4-fold in C57BL/6J mice at $\mathrm{P} 14$ and P16 compared to P12 ( $\left.{ }^{*} P<0.0001 ; \dagger P<0.009\right)$, respectively, but did not result in strain differences between C57BL/6J and 129S3/ SvIM animals. (c) PEDF expression in C57BL/6J control mice increased 1.8- and 2.4-fold at P14 and P16, respectively, compared to P12 $\left({ }^{*} P<0.0002 ; \dagger P<0.0001\right)$. PEDF expression increased to only 1.8-fold in control 129S3/SvIM mice at P16 compared to P12 ( $\left.₫ P<0.02\right)$ but did not differ significantly between P14 and P12 $(P=0.08)$. PEDF expression at at P14 and P16 was increased 1.5- and 1.7-fold, respectively, in C57BL/6J mice compared to $129 \mathrm{~S} 3 / \mathrm{SvIM}$ strain $(\$ P<0.02 ; ¥ P<0.0004)$. (d) TSP-1 expression in C57BL/6J animals increased 2.0- and 2.7-fold at P14 and P16, respectively, compared to P12 ( $\left.{ }^{*} P<0.0001 ; \dagger P<0.0006\right)$. Among 129S3/SvIM mice, TSP-1 mRNA levels increased only 1.7 -fold at P16 compared to P12 $(\ddagger P<0.007)$ with no significant changes between P12 and P14 $(P=0.08)$. TSP-1 expression in C57BL/6J control mice at P14 and P16 was increased 1.4- and 1.9-fold, respectively, compared to 129S3/SvIM animals $(\S P<0.02$; $¥ P<0.004$ ).

TSP-1 mRNA in C57BL/6J was increased during the entire $96 \mathrm{~h}$ course of hypoxia compared to 129S3/SvIM. The source of TSP-1 is likely to be both endothelial and retinal pigment epithelial cells. ${ }^{25,36}$ Consistent with our study, retinal endothelial cells treated with VEGF show an initial decreased TSP-1 expression followed by increased TSP-1 mRNA levels using Northern blot analysis after treatment with VEGF. ${ }^{25}$ Interestingly, we observed the smallest strain-related differences (1.4-fold) in TSP-1 expression at $48 \mathrm{~h}$ hypoxiathe same time at which differences in PEDF expression were absent while strain-related differences in proangiogenic factors VEGF and Ang-2 were observed.

The observed strain-related differences between C57BL/6J and 129S3/SvIM in both PEDF and TSP-1 mRNA expression among developmental control animals at P14 $(P<0.02)$ and P16 $(P<0.004)$ suggest that differential regulation of these growth factors may not only be active during hypoxia-induced angiogenesis. Rather, genetic factors that determine strain-dependent regulation of PEDF and TSP-1 may be inherent to normal vessel development as well as 
influence the extent of activated angiogenesis. Genetic determinants which regulate differential expression of proangiogenic growth factors likely have a distinct mechanism than those which determine differential strain-related differences of antiangiogenic gene expression.

To interpret observed gene expression changes between pro- and antiangiogenic factors within the context of each other, relative levels of VEGF, Ang-2, PEDF, and TSP-1 were determined at the onset of hypoxia ( $0 \mathrm{~h})$; both PEDF and TSP-1 mRNA were increased 20-fold compared to Ang-2 $(P<0.0001)$. Abundant PEDF mRNA levels are consistent with findings that PEDF is highly expressed during the first 2 weeks of murine retinal development. ${ }^{37}$ In contrast, VEGF was increased 10-fold compared to Ang-2 $(P<0.0001)$ in both inbred strains. Alterations in the balance between antiangiogenic and angiogenic growth factors such as VEGF and PEDF may increase or decrease susceptibility to retinal angiogenesis. ${ }^{17,38}$ In patients with retinal neovascularization, decreased levels of PEDF protein in vitreous were found compared to that of controls. ${ }^{39}$ Among diabetic patients with no or mild retinopathy, those with decreased levels of PEDF in aqueous humor collected at cataract surgery developed progressive retinopathy at increased rates by the time of follow-up compared to nonprogressors and control patients. ${ }^{40}$ Overall, genetic influences on the expression of angiogenic inhibitors may have more pronounced effects on angiogenic heterogeneity than variations in expression levels of proangiogenic growth factors.

Processes such as vessel regression or remodeling may also contribute to angiogenic phenotype. Increased PEDF and TSP-1 levels have been implicated in endothelial apoptosis. ${ }^{41-43}$ Increased PEDF and TSP-1 levels observed at $96 \mathrm{~h}$ in C57BL/ 6J may influence strain-related differences in vessel regression and subsequently contribute to decreased angiogenic phenotype observed in these animals.

Identification of single nucleotide polymorphisms (SNPs) with functional alterations in expression levels for VEGF, Ang-2, TSP-1, or PEDF may provide a basis for angiogenesis risk assessment in the clinical setting. Among healthy subjects, interindividual differences in VEGF plasma levels and VEGF gene expression have been associated with variations in $V E G F$ gene sequence. ${ }^{44,45}$ A $936 \mathrm{C} / \mathrm{T}$ mutation in the VEGF $3^{\prime} \mathrm{UTR}$ has been associated with significantly lower VEGF plasma levels in healthy carriers of the 936T allele compared to noncarriers. ${ }^{46}$ SNPs have also been reported for $P E D F$ and TSP-1 genes, and have been implicated in increased risk for ocular and coronary disease. ${ }^{47-49}$ Some SNPs have translated into functional variations in which individuals homozygous for a missense mutation in TSP-1 were found to have lower plasma TSP-1 levels compared to control patients. ${ }^{48}$ Alternatively, the differential expression of pro- and antiangiogenic genes may be due to differential expression of upstream genes that influence angiogenesis including HIF-1 alpha and inflammatory mediators. Our preliminary data shows no difference in expression levels of HIF-1 alpha mRNA between C57BL/6J and 129S3/SvIM strains between 0 and $96 \mathrm{~h}$ of hypoxia in this model (results not shown).

Ultimately, our study suggests that genetic influences may determine differential regulation of both proangiogenic growth factors and angiogenic inhibitors. Interindividual ability to modulate both pro- and antiangiogenic responses may contribute to differences in susceptibility to or severity of angiogenesis-dependent diseases. Further investigation and elucidation of genetic influences on heterogeneic levels of gene expression during angiogenesis may allow us to formulate individualspecific therapy toward or to predict and prevent the progression of a spectrum of diseases.

\section{Acknowledgements}

We thank Roscoe Atkinson MD for assistance in quantitative immunohistochemistry; Laurie Labree for computational advice and statistical analyses; Fernando Gallardo and Lawrence Rife for technical assistance with animal experiments; and Masanori Hangai, MD, PhD, Ernesto Barron, and Anthony Rodriguez for technical assistance with confocal microscopy. This work was supported by grants from the Arnold and Mabel Beckman Foundation, and the National Institute of Health (EY01545 and EY03040). The Doheny Eye Institute is a recipient of an unrestricted grant from Research to Prevent Blindness.

\section{References}

1 Hansen JF. Coronary collateral circulation: clinical significance and influence on survival in patients with coronary artery occlusion. Am Heart J 1989;117: 290-295.

2 Habib GB, Heibig J, Forman SA, et al. Influence of coronary collateral vessels on myocardial infarct size in humans. Results of phase I thrombolysis in myocardial infarction (TIMI) trial. Circulation 1991;83: 739-746.

3 Folkman J, Shing Y. Angiogenesis. J Biol Chem 1992;267:10931-10934.

4 Fidler IJ, Ellis LM. The implications of angiogenesis for the biology and therapy of cancer metastasis. Cell 1994;79:315-328.

5 Lee P, Wang CC, Adamis AP. Ocular neovascularization: an epidemiologic review. Surv Ophthalmol 1998; 43:245-269.

6 Schultz A, Lavie L, Hochberg I, et al. Interindividual heterogeneity in the hypoxic regulation of VEGF: significance for the development of the coronary artery collateral circulation. Circulation 1999;100:547-552.

7 Harris MI, Klein R, Cowie CC, et al. Is the risk of diabetic retinopathy greater in non-hispanic blacks 
and Mexican Americans than in non-hispanic whites with type 2 diabetes? Diabetes Care 1998;21: 1230-1235.

8 Friedman DS, Katz J, Bressler NM, et al. Racial differences in the prevalence of age-related macular degeneration: the Baltimore Eye Survey. Ophthalmology 1999;106:1049-1055.

9 Rohan RM, Fernandez A, Udagawa T, et al. Genetic heterogeneity of angiogenesis in mice. FASEB J 2000; 14:871-876.

10 Gao G, Li Y, Fant J, et al. Difference in ischemic regulation of vascular endothelial growth factor and pigment epithelium-derived factor in Brown Norway and Sprague Dawley rats contributing to different susceptibilities to retinal neovascularization. Diabetes 2002;51:1218-1225.

11 Kitzmann A, Leske D, Chen Y, et al. Incidence and severity of neovascularization in oxygen- and metabolic acidosis-induced retinopathy depend on rat source. Curr Eye Res 2002;25:215-220.

12 Belperio JA, Keane MP, Arenberg DA, et al. CXC chemokines in angiogenesis. J Leukoc Biol 2000;68: 1-8.

13 Carmeliet P. Angiogenesis in health and disease. Nat Med 2003;9:653-660.

14 Chavakis E, Dimmeler S. Regulation of endothelial cell survival and apoptosis during angiogenesis. Arterioscler Thromb Vasc Biol 2002;22:887-893.

15 Bouck N. PEDF: anti-angiogenic guardian of ocular function. Trends Mol Med 2002;8:330-334.

16 Lawler J. Thrombospondin-1 as an endogenous inhibitor of angiogenesis and tumor growth. J Cell Mol Med 2002;6:1-12.

17 Barnstable CJ, Tombran-Tink J. Neuroprotective and antiangiogenic actions of PEDF in the eye: molecular targets and therapeutic potential. Prog Retin Eye Res 2004;23:561-577.

18 Chan CK, Pham LN, Chinn C, et al. Mouse straindependent heterogeneity of resting limbal vasculature. Invest Ophthalmol Vis Sci 2004;45:441-447.

19 Rogers MS, Rohan RM, Birsner AE, et al. Genetic loci that control vascular endothelial growth factor-induced angiogenesis. FASEB J 2003;17:1050-1059.

20 Dor Y, Porat R, Keshet E. Vascular endothelial growth factor and vascular adjustments to perturbations in oxygen homeostasis. Am J Physiol Cell Physiol 2001;280:C1367-C1374.

21 Mandriota SJ, Pyke C, Di Sanza C, et al. Hypoxiainducible angiopoietin-2 expression is mimicked by iodonium compounds and occurs in the rat brain and skin in response to systemic hypoxia and tissue ischemia. Am J Pathol 2000;156:2077-2089.

22 Oh H, Takagi H, Suzuma K, et al. Hypoxia and vascular endothelial growth factor selectively up-regulate angiopoietin-2 in bovine microvascular endothelial cells. J Biol Chem 1999;274:15732-15739.

23 Guo N, Krutzsch HC, Inman JK, et al. Thrombospondin 1 and type I repeat peptides of thrombospondin 1 specifically induce apoptosis of endothelial cells. Cancer Res 1997;57:1735-1742.

24 Shafiee A, Penn JS, Krutzsch HC, et al. Inhibition of retinal angiogenesis by peptides derived from thrombospondin-1. Invest Ophthalmol Vis Sci 2000;41: 2378-2388.

25 Suzuma K, Takagi H, Otani A, et al. Expression of thrombospondin-1 in ischemia-induced retinal neovascularization. Am J Pathol 1999;154:343-354.
26 Smith LEH, Wesolowski E, McLellan A, et al. Oxygeninduced retinopathy in the mouse. Invest Ophthalmol Vis Sci 1994;34:101-111.

27 Madan A, Penn JS. Animal models of oxygen-induced retinopathy. Front Biosci 2003;8:D1030-1043.

28 Asahara $\mathrm{T}$, Chen $\mathrm{D}$, Takahashi $\mathrm{T}$, et al. Tie2 receptor ligands, angiopoietin-1 and angiopoietin-2 modulate VEGF-induced postnatal neovascularization. Circ Res 1998;83:233-240.

29 Ozaki H, Seo MS, Ozaki K, et al. Blockade of vascular endothelial cell growth factor receptor signaling is sufficient to completely prevent retinal neovascularization. Am J Pathol 2000;156:697-707.

30 Russell SR, Shepherd JD, Hageman GS. Distribution of glycoconjugates in the human retinal internal limiting membrane. Invest Ophthalmol Vis Sci 1991; 32:1986-1995.

31 Fink L, Seeger W, Ermert L, et al. Real-time quantitative RT-PCR after laser-assisted cell picking. Nat Med 1998;4:1329-1333.

32 Pierce EA, Avery RL, Foley ED, et al. Vascular endothelial growth factor/vascular permeability factor expression in a mouse model of retinal neovascularization. Proc Natl Acad Sci 1995;92:905-909.

33 Hackett SF, Ozaki H, Strauss RW, et al. Angiopoietin 2 expression in the retina: upregulation during physiologic and pathologic neovascularization. J Cell Physiol 2000;184:275-284.

34 Hackett SF, Wiegand S, Yancopoulos G, et al. Angiopoietin-2 plays an important role in retinal angiogenesis. J Cell Physiol 2002;192:182-187.

35 Ohno-Matsui K, Yoshida T, Uetama T, et al. Vascular endothelial growth factor upregulates pigment epithelium-derived factor expression via VEGFR-1 in human retinal pigment epithelial cells. Biochem Biophys Res Commun 2003;303:962-967.

36 Miyajima-Uchida $\mathrm{H}$, Hayashi $\mathrm{H}$, Beppu $\mathrm{R}$, et al. Production and accumulation of thrombospondin-1 in human retinal pigment epithelial cells. Invest Ophthalmol Vis Sci 2000;41:561-567.

37 Behling KC, Surace EM, Bennett J. Pigment epithelium-derived factor expression in the developing mouse eye. Mol Vis 2002;8:449-454.

38 Dawson DW, Volpert OV, Gillis $\mathrm{P}$, et al. Pigment epithelium-derived factor: a potent inhibitor of angiogenesis. Science 1999;285:245-248.

39 Spranger J, Osterhoff M, Reimann M, et al. Loss of the antiangiogenic pigment epithelium-derived factor in patients with angiogenic eye disease. Diabetes 2001; 50:2641-2645.

40 Boehm BO, Lang G, Volpert O, et al. Low content of the natural ocular anti-angiogenic agent pigment epithelium-derived factor (PEDF) in aqueous humor predicts progression of diabetic retinopathy. Diabetologia 2003; 46:394-400.

41 Mori K, Gehlbach P, Ando A, et al. Regression of ocular neovascularization in response to increased expression of pigment epithelium-derived factor. Invest Ophthalmol Vis Sci 2002;43:2428-2434.

42 Jiménez B, Volpert OV, Crawford SE, et al. Signals leading to apoptosis-dependent inhibition of neovascularization by thrombospondin-1. Nat Med 2000;6:41-48.

43 Volpert OV, Zaichuk $\mathrm{T}$, Zhou $\mathrm{W}$, et al. Inducerstimulated Fas targets activated endothelium for destruction by anti-angiogenic thrombospondin-1 and pigment epithelium-derived factor. Nat Med 2002;8: 349-357. 
44 Renner W, Pilger E. Simultaneous in vivo quantitation of vascular endothelial growth factor mRNA splice variants. J Vasc Res 1999;36:133-138.

45 Watson CJ, Webb NJ, Bottomley MJ, et al. Identification of polymorphisms within the vascular endothelial growth factor (VEGF) gene: correlation with variation in VEGF protein production. Cytokine 2000;12: 1232-1235.

46 Renner W, Kotschan S, Hoffmann C, et al. A common $936 \mathrm{C} / \mathrm{T}$ mutation in the gene for vascular endothelial growth factor is associated with vascular endothelial growth factor plasma levels. J Vasc Res 2000;37: 443-448.
47 Koenekoop R, Pina AL, Loyer M, et al. Four polymorphic variations in the PEDF gene identified during the mutation screening of patients with Leber congenital amaurosis. Mol Vis 1999;5:10.

48 Topol EJ, McCarthy J, Gabriel S, et al. Single nucleotide polymorphisms in multiple novel thrombospondin genes may be associated with familial premature myocardial infarction. Circulation 2001;104:2641-2644.

49 Hannah BL, Misenheimer TM, Annis DS, et al. A polymorphism in thrombospondin-1 associated with familial premature coronary heart disease causes a local change in conformation of the Ca2+-binding repeats. J Biol Chem 2003;278:8929-8934. 